\title{
Desenvolvimento da promoção da saúde no Brasil nos últimos vinte anos (1988-2008)
}

\author{
Development of health promotion in Brazil \\ in the last twenty years (1988-2008)
}

Paulo M archiori Buss ${ }^{1}$

Antonio Ivo de Carvalho ${ }^{1}$

\footnotetext{
${ }^{1}$ Escola Nacional de Saúde

Pública Sérgio Arouca,

Fundação Oswaldo Cruz.

Rua Leopoldo Bulhões

1480/70 andar, M anguinhos.

21041-210 Rio de Janeiro

RJ. buss@fiocruz.br
}

Abstract This paper examines the institutionalization of health promotion (HP) in Brazil in the twenty years following the proclamation of the 1988 Brazilian Constitution. The legal and institutional foundations of HP are delineated, as well as its recent reassertion as a national policy. M oreover, the praxis of HP within the health system and other instances are analyzed, and the institutional capacity building - by means of research and training of human resources - is examined. Around 100 papers were revised, including institutional policy documents, decrees, laws, and annals of congresses and other events. The authors' personal experience in the ideational conception of the area and in the institutionalization of health promotion as a public policy in the country was also drawn upon. Finally, major restrictions to the theoretical and practical development of health promotion are criticized and a few ideas that might benefit such development are presented.

Key words Health promotion in Brazil, Health system, Brazilian Constitution
Resumo 0 presente artigo examina o desenvolvimento da institucionalização da promoção da saúde (PS) no Brasil nos últimos vinte anos, desde a Constituição Federal de 1988. Aborda, inicialmente, 0 arcabouço jurídico-institucional sobre o qual repousa a institucionalização da PS no país. A seguir, trata desua afirmação recentecomo política nacional, da análise de suas práticas se gundo se desenvolvam no interior do sistema de saúde ou em outras instâncias e, finalmente, da construção da sua capacidade institucional, através da pesquisa e da formação de recursos humanos. Foram revisados cerca de cem referências bibliográficas, entre documentos de política institucional, decretos e leis, anais de congressos e outros eventos. A vivência pessoal dos autores no processo de desenvolvimento teórico-conceitual da área e do processo de institucionalização da promoção da saúde como política pública no país também foi aproveitada na produção desta revisão. 0 artigo finaliza com uma crítica sobre as principais restrições ao seu desenvolvimento teórico-prático e a indicação de algumas perspectivas que favoreceriam tal desenvolvimento. Palavras-chave Promoção da saúde no Brasil, Sistema de saúde, Constituição brasileira 
Introdução

0 presente artigo aborda a institucionalização da promoção da saúde (PS) no Brasil nos últimos vinte anos, após a Constituição Federal de 1988. Surgidos vigorosamente a partir da I Conferência Internacional sobre Promoção da Saúde $^{1}$, realizada em Ottawa, em 1986, conceitos e práticas de PS passaram a ser divulgados e implementados desde então em sistemas de saúdee espaços acadêmicos detodo o mundo, bem como no Brasil ${ }^{2-17}$. Contudo, raros esforços ${ }^{18-20}$ foram feitos para avaliar a forma quetal conceito e suas práticas dominantes adquiriram no Brasil, o que pretendemos fazer no presente trabal ho.

0 artigo analisa a trajetória da PS como política nacional, examina suas práticas no interior do sistema desaúdeeem outrasinstâncias eaborda a construção da sua capacidade institucional através da pesquisa e da formação de recursos humanos. Finaliza com uma crítica sobreas principais restrições ao seu desenvolvimento teóricoprático ea indicação de al gumas perspectivas que poderiam favorecer tal desenvolvimento.

Os marcos legais e institucionais da PS no Brasil são contemporâneos à I Conferência Internacional sobre Promoção da Saúde, realizada em Ottawa, no Canadá, em 1986. N esse mesmo ano, realizou-se no país a VIII Conferência N acional de Saúde que, no contexto da redemocratização, após a ditadura militar, envolveu grande partici pação de profissionais, gestores ecidadãos e propôs as bases do que se viria denominar "reforma sanitária brasileira", cujos princípios e diretrizes muito próximos aos conceitos centrais da PS foram incorporados na Constituição $\mathrm{Fe}$ deral de 1988, outorgada pela Assembléia N acional Constituinte 21,22 .

\section{A promoção da saúde como política nacional}

Em 1992, num contexto de expansão equalificação da atenção básica, inicia-se o primeiro programa, depois transformado em política estruturada, a se inspirar e operar com preceitos de PS. Trata-se do Programa Saúde da Família (PSF) ${ }^{23,24}$, que nesta época o M inistério da Saúde (MS) formula e começa a implementar ainda timidamente, entendendo-o como uma "estraté gia" de reorientação do modelo assistencial, operacionalizada mediante a implantação de equipes multiprofissionais em unidades básicas de saúde. As equipes atuam com ações de promo- ção da saúde, prevenção, recuperação, reabilitação de doenças e agravos mais frequentes, e na manutenção da saúde da comunidade.

Entre 1998 e 1999, a PS ganha al guma institucionalidade no M S com a formalização do projeto "Promoção da Saúde, um novo modelo de atenção", em cooperação com o Programa das Nações Unidas para o Desenvolvimento (PNUD) ${ }^{25}$. Inicia-se, assim, um esforço de introdução formal do tema no debate da saúde no país, o queinclui o lançamento da revista Promoção da Saúde (da qual se publicam sete números, infelizmente esgotados, entre 1999 e 2002) e a publicação das Cartas da Promoção da Saúde $e^{3}$, com artigo introdutório de um dos autores do presente trabalho ${ }^{4}$.

Nessa época, a partir do sucesso do seu programa de controle do tabagismo, o Brasil teve papel destacado, no contexto mundial da PS, na elaboração do Tratado Internacional para o Controle do Tabaco, desenvolvido no âmbito da OM S; assumiu, em 2000, a presidência do Órgão deN egociação Internacional, função que manteveno transcorrer detodo o processo, que culminou com a aprovação da Convenção Quadro pela 56a Assembléia M undial de Saúde, em 2003, ao qual o Brasil adere no mesmo ano.

Em 2002, o M S elaborou o documento intitulado "Política Nacional de Promoção da Saú$\mathrm{de}^{\prime \prime 26}$, quenunca tevevigência integral real no interior do sistema de saúde; contudo, trata-se de um registro importante de proposta formal de "política de promoção da saúde" na esfera federal. N este contexto, foram elaborados diversos documentos, nas áreas de alimentação saudável eatividadefísica ${ }^{27}$; violência no trânsito ${ }^{28}$; o projeto "Agita Brasil"29, a proposta de promoção da saúde na escola, entre outros.

O projeto de PS desta época teve apoio do PNUD e enquadrou-se nos esforços de implementação do programa "Comunidade Solidária", que reunia esforços de diferentes ministérios relacionados com o desenvolvimento local integrado e sustentável, como Alfabetização Solidária, TV Escola, Salto para o Futuro, Agricultura Familiar, Projeto Alvorada e o DLIS, propriamentedito.

Logo após o lançamento da Estratégia Global para Alimentação Saudável, Atividade Física e Saúde, pela OM S30 e diante do quadro epidemiológico e defatores de risco vigentes (taxas de mortalidade por doenças crônicas não-transmissíveis elevadas, al tosíndices deinatividadefísicae padrões alimentares dominantes inadequados), o M S decide, em abril de2004, instituir einiciar a 
difusão da Estratégia no país ${ }^{31}$. 0 MS inicia 0 programa "Pratique Saúde" 32 .

Em julho de 2005, através da Portaria MS no 1.190, foi instituído o Comitê Gestor da Política Nacional de Promoção da Saúde (CGPNPS), composto por representantes dos diversos segmentos do M S, mas apenas deste, sem a participação das outras esferas de governo ou da sociedade civil. Além de propor a política, o comitê deveria consolidar a "Agenda Nacional de Promoção da Saúde 2005-2007"26.

Em março de 2006, através da Portaria M S n ${ }^{\circ}$ $687^{33}$, o M S formalizou a política de PS no SU S, a partir da formulação feita pelo mencionado comitê, articulando e reforçando diversas iniciativas promocionais, definindo como diretrizes:

- Consolidar a proposta da PNPS e de sua agenda nacional;

- Coordenar sua implantação e articulação com os demais setores governamentais e nãogovernamentais;

- Incentivar estados e municípios a elaborar planos de PS;

- Articular e integrar ações de PS no SUS;

- Monitorar e avaliar as estratégias de implementação da PN PS e seu impacto; dade;

- Reconhecer a importância da PS para a equi-

. Estimular as ações intersetoriais;

. Fortalecer a participação social (empoderamento);

- Adotar práticas horizontais de gestão e estabelecimento de redes de cooperação intersetoriais;

- Incentivar a pesquisa e avaliação em PS;

- Viabilizar iniciativas de PS junto aos trabaIhadores e usuários do SUS, considerando metodologias participativas e o saber popular e tradicional.

Também em março de 2006, apenas um ano depois do lançamento da Comissão sobre $\mathrm{De}$ terminantes Sociais da Saúde pela O M S34, o próprio Presidente da República instituiu a Comissão Nacional sobre Determinantes Sociais da Saúde (CN DSS), no âmbito do MS, a primeira a se constituir no mundo. A CNDSS foi composta por dezesseis personalidades de diversas áreas da vida social nacional e de um grupo interministerial, envolvendo dezesseis ministérios das áreas econômicas e sociais, além de representantes das SES e SM S e da OPS/Brasil, e apresentou, em abril de 2008, seu relatório final, intitulado "As causas sociais das iniquidades em saúde no Brasil"35. O relatório ficou em consulta pública entrefevereiro emarço de 2008, recebendo diversas contribuições.
As principais recomendações da CNDSS incluem a criação de uma Câmara de Políticas Sociais no Gabinete Civil da Presidência da República para realizar a necessária articulação intersetorial, no plano federal, das políticas públicas que têm reconhecidas influências sobre a saúde. Uma secretaria executiva - na forma de Secretaria Nacional de Promoção da Saúde e Atenção Básica - seria criada no MS, outorgando a este campo à devida prioridade. De fato, a coordenação da área da PS tinha sua localização na "divisão de doenças crônicas não-transmissíveis", no interior da Secretaria deV igilância em Saúde, estrutura responsável, no M S, pela política de"controle de doenças". Esta era, possivelmente, uma das causas para a baixa prioridade atribuída até então à PS no M S e uma visão reducionista quea mantinha restrita ao âmbito da prevenção de riscos ou doenças. Toda esta nova estrutura encontra-se em pleno processo de montagem, esperando-se que surta os efeitos devidos no transcorrer de 2010 e anos seguintes.

Com o lançamento do programa "M ais Saúde: Direito de Todos, 2008-2011"36, o campo da PS recebeu extraordinário destaque, constituindo-se num dos sete eixos de intervenção, ao lado da atenção à saúde, complexo industrial da saúde, força de trabalho em saúde, qualificação da gestão, participação e controle social e cooperação internacional.

A maioria das ações e iniciativas de PS apresentadas e discutidas a seguir, entretanto, por terem sido formuladas e implementadas até 2007, desenvolveram-se ainda fora das propostas da PN PS e da CNDSS e também do "M ais Saúde". Em artigo futuro, os autores analisarão os desdobramentos da PS no contexto da política de saúde proposta pelo "Mais Saúde", em implementação pelo M S no último ano (2008), com expectativas de resultados em 2009-2010.

\section{Promoção da saúdecomo serviços, ações, estratégias}

As ações de PS no Brasil são muito diversificadas, como ocorre em qualquer país ou sistema de saúde. Em termos de "foco" podem estar dirigidas a indivíduos, grupos de população específicos ou a toda população. Quanto ao "objeto", podem abranger um único problema de saúde, sensível às ações de promoção, ou serem abrangentes, propondo-se, por exemplo, a enfrentar os "determinantes sociais da saúde" como um todo. Em termos de "campo de ação", podem 
mobilizar um único dos campos propostos na Carta de Ottawa ou incluir simultaneamente vários deles. Com respeito à "ênfase" conferida, podem identificar-se apenas com ações educativas ou com ações mais abrangentes de saúde, qualidade de vida e desenvolvimento. Podem ser implementadas no âmbito de políticas públicas universais do sistema de saúde ou por organizações privadas, exclusivamente para seus membros. No caso da política pública, podem ser uma iniciativa do governo federal ou de um governo estadual ou local. Além dessas, muitas outras"categorias" poderiam ser invocadas para caracterizar a PS no Brasil.

Para apresentar de forma didática a complexidade e abrangência destas ações, optamos por alinhar de forma crítica as iniciativas conhecidas, conforme se situem:

- No espaço dos serviços de saúde

- No espaço das políticas intersetoriais e de desenvolvimento

No espaço dos serviços de atenção à saúde, individuais ou coletivos

Como foi dito, a própria configuração institucional do SUS atende a diversos preceitos da PS; entretanto, o seu funcionamento na prática ainda carece de mai or expansão de práticas promocionais. Ressaltamos, a seguir, a iniciativa que consideramos paradigmática da reorientação e inovação do SUS, à luz de estratégias promocionais, que tende a se universalizar no sistema de saúde do país: o Programa Saúde da Família ${ }^{23,24}$.

Programa Saúde da Família (PSF)

O PSF iniciou em 1992, com o Programa de Agentes Comunitários de Saúde (PACS), visando implementar ações básicas custo-efetivas em populações pobres (reidratação oral, aleitamento materno, educação, etc.), com o objetivo fundamental de reduzir a mortalidade infantil. Evoluiu, graças ao reconhecido êxito do programa, para o que hoje é conceituado como "estratégia da saúde da família" que, segundo seus condutores políticos, visa à conversão do modelo assistencial do sistema de saúde, através da expansão do PSF e da indução da oferta de média e alta complexidade adequada aos preceitos da integralidade e da qualidade da atenção.

Segundo dados do MS, o PSF estava constituído, em dezembro de 2008, de 29,3 mil equipes em cerca de 5.235 municípios, cuja população total é de cerca de 89,3 milhões de habitantes ${ }^{37}$. Cada equipe é composta, no mínimo, por um médico defamília, um enfermeiro, dois auxiliares de enfermagem e um número variável de agentes comunitários de saúde (ACS). No final de 2008, 0 MS registrava a existência de 230,2 mil ACS e 0 PACS estava presenteem 5.354 municípios. Quando ampliada com a saúde oral, a equipe de SF conta ainda com dentista, auxiliar de consultório dentário etécnico em higienedental. As equipes desaúde oral eram cerca de 17,8 mil, no final de 2008. Todos os trabalhadores têm jornada de trabalho de quarenta horas semanais.

Cada equipe se responsabiliza pelo acompanhamento de cerca de 3 a 4,5 mil pessoas ou de mil famílias de determinada área. A atuação das equipes ocorre principalmente nas unidades básicas de saúde, nas residências e na mobilização da comunidade, caracterizando-se ${ }^{24}$ : como porta de entrada de um sistema hierarquizado e regionalizado de saúde; por ter território definido, com uma população delimitada, sob a sua responsabilidade; por intervir sobre os fatores de risco aos quais a comunidade está exposta; por prestar assistência integral, permanentee de qualidade; por realizar expressivo conjunto de atividades de educação e promoção da saúde.

$E$, ainda24: por estabelecer vínculos de compromisso e de corresponsabilidade com a população; por estimular a organização das comunidades para exercer o controle social das ações e serviços de saúde; por utilizar sistemas de informação para o monitoramento e a tomada de decisões; e por atuar de forma intersetorial, por meio de parcerias estabelecidas com diferentes segmentos sociais einstitucionais, intervindo em situações que transcendem a especificidade do setor saúde e que tenham efeitos determinantes sobre as condições de vida e saúde dos indivíduos-famílias-comunidade, o que são, conceitualmente, ações de PS.

0 controle do crescimento e desenvolvimento infantil, 0 atendimento ao calendário deimunizações, o acompanhamento pré-natal, o estímulo ao aleitamento materno, a promoção de melhores condições de higiene domiciliar e pessoal, bem como do acesso aos recursos de água, esgoto e destinação do lixo estão entre as principais ações de PS do PSF, voltadas para as pessoas e o núcleo familiar. Inúmeros trabalhos ainda não publicados têm realçado os efeitos positivos da saúde da família e das ações de PS sobre determinados indicadores de saúde, com redução da mortalidadeinfantil, da desnutrição infantil e dos partos prematuros, assim como do aumento dos partos normais versus o parto por cesarianas e da amamentação ao peito, entre outros. 
D os 3.665 trabal hos apresentados nallI M ostra Nacional de Produção em Saúde da Família ${ }^{38}$, realizada em agosto de 2008, em Brasília (DF), 185 diziam respeito às ações intersetoriais, 168 à integralidade do cuidado, 266 à vigilância em saúde, 88 ao controle social, 867 à promoção da saúde e 419 às tecnologias do cuidado. Pelas razões antes expostas e pela produção dos profissionais de SF apresentadas nesta mostra de 2008 (e nas anteriores), é mister concluir pela íntima relação entre Promoção da Saúde e Saúde da Família e a importância desta última na implementação de ações e práticas, bem como na geração de conhecimentos em PS.

Política Nacional de Alimentação

e Nutrição (PNAN)

Como pano de fundo da PNAN ${ }^{39}$, o Brasil adotou o conceito de segurança alimentar e nutricional, entendido como a garantia, a todos, de condi ções de acesso a alimentos básicos de qualidade, em quantidade suficiente, de modo permanente e sem comprometer o acesso a outras necessidades básicas como saúde, educação, moradia, trabaIho, lazer [...], com base em práticas alimentares que contribuam para uma existência digna, em um contexto de desenvolvimento integral da pessoa humana ${ }^{39}$.

Através desta política - implementada em estreita articulação com o PSF - tem havido grande estímulo às seguintes práticas de PS:

- aleitamento materno exclusivo até os seis meses de vida e até os dois anos intercal ado com outros alimentos;

- implementação do código internacional de regulação do marketing de substitutos do leite materno, área na qual o Brasil possui ampla experiência eum razoável sucesso, com sua regulamentação em 1988 e revisões em 1992 e 200140;

- introdução, no âmbito do programa de escolas promotoras da saúde, da educação alimentar de escolares e do fomento a cantinas saudáveis nas escolas;

- regulação da propaganda de al imentos para crianças nos meios de comunicação, principalmente a televisão;

. obrigatoriedade da rotulagem nutricional de produtos industrializados e embalados, iniciada no Brasil em 2002, com o objetivo de garantir 0 direito à informação do cidadão-consumidor eauxiliar na seleção e aquisição dealimentos saudáveis ${ }^{41}$;

. suplementação de vitamina $\mathrm{A}^{42}$;

- obrigatoriedade de adição universal de iodo ao sal de cozinha e de ferro eácido fólico às fari- nhas consumidas pela populaçãa ${ }^{43}, 0$ que resultou na eliminação do bócio endêmico e na expressiva redução da anemia ferropriva e outras no país;

- publicação do Guia Alimentar para a População Brasileira ${ }^{44}$, com distribuição para as equipes de saúde da família, ON Gs, imprensa, etc.

A PNAN, como parte essencial da política nacional de PS, continua em evolução e aperfeiçoamento. A Agência N acional de Vigilância Sanitária (ANVISA) do M S colocou em consulta públi$\mathrm{Ca}^{45}$ a proposta de resolução com regras para propaganda, publicidade, promoção e informação de alimentos, cujo objetivo é diminuir o avanço das doenças crônicas não transmissíveis, em especial junto ao público infantil, a partir da restrição da publicidade dealimentos potencialmenteprejudiciais à saúde (comidas ricas em açúcar, sal e gorduras, além de refrigerantes erefrescosartificiais).

\section{Outras iniciativas}

Diversas outras iniciativas desenvolvem-se sob a coordenação da PN PS e seguindo suas diretrizes, algumas em âmbito intersetorial e outras exclusivamente no interior da política e do sistema de saúde, visando às situações específicas de saúde e levando em conta o risco diferencial que representam segundo os determinantes sociais. Os campos alcançados estão relacionados abaixo e uma visão completa dos documentos a eles referidos está disponível nos diversos segmentos do site do $\mathrm{M} \mathrm{S}^{46}$, aos quais remetemos os leitores interessados:

- promoção da prática corporal e da atividade física ${ }^{27,29}$

. prevenção e controle do tabagismo ${ }^{47,48}$;

- prevenção do uso abusivo de álcool e outras drogas ${ }^{49}$;

- prevenção dos acidentes de trânsito e suas consequências ${ }^{28}$;

- promoção da cultura da paz e prevenção da violência ${ }^{28,91 ;}$

. educação em DST/aids 50-52;

. ações de comunicação como estratégia para a PS 53 ;

. participação social e empoderamento ${ }^{54-57}$;

- promoção de equidade e qualidade de vida;

- desenvolvimento sustentável e saúde ambiental58;

. avaliação da PS ${ }^{13}$.

Uma área que merece especial referência pela sua tradição nos serviços de saúdeno Brasil éa da educação em saúde que, por muito tempo, foi uma das poucas atividades organizadas de PS no 
país, confundindo-se com o próprio campo. $M$ anifesta-se por duas vertentes principais, a educação em saúde clássica e mais tradicional, praticada em serviços de atenção básica como os da antiga Fundação SESP, e a que se vincula ao campo da chamada "educação popular em saúde". Esta surge na virada da década de oitenta para noventa, quando é criada a Articulação $\mathrm{N}$ acional de Educação Popular em Saúde. Alguns livros publicados sobre esta vertente ${ }^{59,60}$ foram decisivos para a formulação de projetos acadêmicos e de práticas em serviços de saúde, bem como para a construção teórico-conceitual da área.

No espaço das políticas públicas de desenvolvimento, da intersetorialidade e da ação comunitária

Descrevemos, neste tópico, diversas iniciativas dePS, de naturezaintersetorial, envolvendo a partici pação de diversas áreas governamentais e da sociedade.

Programa Bolsa Família (PBF)

$0 \mathrm{PBF}^{61}$ é um programa de transferência direta de renda com condicionalidades, que beneficia famílias pobres (renda mensal por pessoa de $R \$ 60,01$ a $R \$ 120,00$ ) e extremamentepobres (renda mensal por pessoa de até $\mathrm{R} \$ 60,00$ ). $R e$ sulta da pactuação entre Governo Federal, estados e municípios, com a intenção de potencializar a ação de todos no combate à pobreza. $\mathrm{A}$ decisão de que famílias vão receber o benefício do Bolsa Família é de um conselho ao nível dos municípios. A concessão do cartão bancário que dá acesso aos recursos por parte da família é entregue à mulher, pois é ela, em geral, que se responsabiliza pelos cuidados à prole e pela gestão da economia doméstica.

Ao entrar no PBF, a família se compromete a manter crianças e adolescentes frequentando a escola e a cumprir cuidados básicos em saúde: calendário de vacinação, para crianças entrezero e seis anos, e agenda prée pós-natal para gestantes e mães em amamentação.

Dados recentes ${ }^{61}$ informam que o PBF está presenteem todosos municípios brasileiros; que seus gastos anuais ascendem à cerca de $R \$ 10,3$ bilhões (cerca de USD 5 bilhões); e que cerca de 11,1 milhões de famílias e 45 milhões de pessoas estão cobertas, o que o transforma num dos maiores programas de transferência de renda da América Latina. Contudo, não é possível estimar quantas famílias e pessoas vulneráveis e elegíveis para o programa ainda estão por ser cobertas.
O PBF é operado pelo M inistério do Desenvolvimento Social, não tendo relações formais com o MS ou com outros ministérios setoriais. Contudo, são nítidas as relações entre o PBF e a PS, não só pelas condicionalidades exigidas, como pelo asseguramento de alimentação mínima para a família e o impulso que tais recursos têm trazido ao desenvolvimento local de inúmeras regiões pobres do país, com evidentes externalidades nos campos da saúde e da qualidade de vida.

Estudos recentes ${ }^{61}$ mostraram queo PBF está bem focalizado, ou seja, efetivamente chega às famílias que dele necessitam e que atendem aos critérios da lei equecontribui deforma significativa para a redução da extrema pobreza e da desigualdade epara a melhoria da situação alimentar enutricional das famílias beneficiárias.

Há, por outro lado, o esforço de articular, no plano local, o PBF com iniciativas setoriais como, por exemplo, nas áreas rurais pobres do país, com a agricultura familiar ou o desenvolvimento territorial integrado e sustentável, ambos gerenciadospelo M inistério do Desenvolvimento Agrário (M DA) emunicípios; estas iniciativas buscam estimular a produção de alimentos por meio da prática da agricultura familiar e de subsistência versus a agroindústria voltada para a exportação, bem como integrar políticas públicas em territórios rurais. Estabelece-se, assim, um "círculo virtuoso", pelo qual os recursos do PBF estimulam o consumo alimentar, asseguram um melhor nível de saúdee nutrição egarantem a sustentabilidade da agricultura familiar e do desenvolvimento nos locais onde este arranjo se estabelece.

Cidades/comunidades saudáveis

"Cidades/municípios/comunidades saudáveis" é estratégia de implementação da PS reconhecida em todo o mund0 ${ }^{62-64}$. A pesar de tal relevância, apenas iniciativas limitadas de cidades/ comunidades saudáveis estão em curso no Brasil sem, contudo, organizarem-senacionalmente. São iniciativas localizadas em microrregiões, que em geral reúnem como parceiros principaisas prefeituras e universidades, às quais podem se agregar outros atores sociais. Contudo, o tema "cidades saudáveis" ainda não ganhou realce no Brasil e, tampouco, alcançou instâncias politicamente mais relevantes, como o M S e o Conselho Nacional dos Secretários Municipais deSaúde(CONASEM S) ou, o que seria mais indicado, organismosquereúnem prefeituras e/ou prefeitos do país. A seguir, descrevemos al gumas destas iniciativas.

Uma das primeiras referências consistentes sobremunicípiossaudáveisno Brasil, relacionan- 
do-os com uma agenda para a saúde e o SUS, encontra-se no trabalho de $M$ endes ${ }^{65}$, quando propõe a necessidade de um 'novo paradigma sanitário' e, neste contexto conceitual, uma “mudança da ordem governativa nas cidades" e a PS como uma das estratégias de interven ção da "vigilância da saúde". 0 mesmo autor aprofunda suas propostas em obras subsequentes ${ }^{66,67}$. Ferraz ${ }^{68}$, também na década de noventa, publica livro sobrecidades saudáveis, com elementos conceituais ebrevedescrição de experiências nacionais.

A RedeBrasileira deM unicípiosPotencialmente Saudávei $5^{69,70}$, criada em 2003, conta hoje com 27 municípios do Estado de São Paulo, nos quais vivem cerca de 2 milhões de habitantes. As prioridades dos governos municipais ligados à rede estão agrupadas em cinco eixos temáticos (saúde, meio ambiente, participação social, geração de renda, segurança), que são pontos de partida ou de foco, a partir dos quais os municípios desenvolvem suas políticas públicas. A rede visa apoiar os municípios em: (1) desenvolver ações intersetoriais e transetoriais; (2) fortalecer os diferentes atores sociais no sentido da participação transformadora e busca da autonomia; (3) construir práticas que firmem os valores e desejos dos atores sociais em relação ao seu território, para que assim colaborem para o desenvolvimento local saudável esustentável, respeitando os critérios de equidade social; (4) divulgar experiências de sucesso nos municípios dentro e fora da rede.

Também no Estado de São Paulo, sob a liderança da Faculdade de Saúde Pública da USP, constituiu-se desdeo ano 2000 o M ovimento por Cidades e Municípios Saudáveis ${ }^{71,72}$, uma rede de seis municípios (Bertioga, Itaoca, Lins, M otuca, Ribeira e São Paulo) reunidos em torno do conceito e práticas das cidades saudáveis. Os projetos de cada um dos municípios têm características próprias edevariável teor (descritos em http:/ /www.cidadessaudaveis.org.br). Em Pernambuco, a U FPE e parceiros lançaram, em 2005, a iniciativa Municípios Saudáveis no Nordeste do Brasil ${ }^{73}$, com cinco municípios.

Uma experiência pioneira emuito consistente vem sendo desenvolvida já alguns anos em Curitiba (PR) ${ }^{74}$. Esta experiência ea deFortal eza (CE) foram exaustivamente analisadas por Andrade ${ }^{75}$ em livro recente.

Existem também outras iniciativas inspiradas em princípios da PS, em geral de âmbito local ou sub-regional, as chamadas "comunidades saudáveis". Um exemplo éa Rede de Comunidades Saudáveis do Rio de Janeiro ${ }^{76,77}$, criada em 2005 ereunindo hojecerca de 106 comunidades.
Escolas promotoras da saúde

A estratégia das escolas promotoras da saúde está em expansão no país, com a multiplicação de projetos e programas orientados para 0 fomento de práticas saudáveis entre professores e alunos da rede escolar. Tais programas envolvem parcerias entre diversas áreas do M S com o M inistério da Educação, universidades, estados emunicípios.

Experiências auspiciosas vêm sendo implementadas pelas prefeituras do Rio de Janeiro ${ }^{78} \mathrm{e}$ Santos ${ }^{79}$, ao lado de muitas outras implementadas por estados e municípios. Por outro lado, a Sociedade Brasileira de Pediatria tem sido ativa na difusão da matéria, tendo editado cadernos sobre as escolas promotoras da saúde ${ }^{80}$, assim como a OPS, através de traduções de documentos da Rede Latino-americana de Escolas Promotoras da Saúde, da qual fazem parte inúmeras experiências brasileiras.

Outras experiências

de desenvolvimento local

Desenvolveram-se no Brasil, nos últimos anos, experiências de desenvolvimento local que ganharam identidades variáveis; muitas delas inspiram-se e tomam como ponto de partida os princípios da PS. Em 2003, a ABRASCO criou 0 Grupo de Trabalho sobre Promoção da Saúde e Desenvolvimento Local, Integrado eSustentáve ${ }^{81}$, que exerce o papel de articulador e impulsionador dessas experiências, agregando hoje cerca de cinquenta grupos. Os dois informes já publicados pelo GT ${ }^{82,83}$ concluíram queestas experiências desenvolvem-se de forma desigual no país, dependendo, para o seu êxito, da articulação local de atores da gestão pública, das universidades, da mobilização comunitária e, eventualmente, de empresas. Carecem também de uma articulação mais abrangente, não havendo nenhuma iniciativa governamental nacional propiciadora dessa estratégia de PS. 0 tema da saúde e desenvolvimento local foi alvo deanáliseno contexto latino-americano, que incluiu o Brasi ${ }^{84}$.

Entre as experiências mais significativas, encontra-se o DLIS M anguinhos ${ }^{6,10,85}$, desenvolvido a partir de meados dos anos noventa numa comunidade carente de cerca de 50 mil moradores, nos arredores da Fiocruz, no Rio de Janeiro. 0 projeto, liderado pela EN SP/Fiocruz e apoiado pela cooperação canadense (CIDA-CPHA), reúne gestores governamentais, empresas, instituições civis e organizações comunitárias em torno de projetos locais em saúde, saneamento, educa- 
ção, habitação, geração de emprego e renda, esporte e lazer. 0 projeto logrou importante mobilização da comunidade, o que certamente influenciou na escolha de $M$ anguinhos como uma das áreas do PAC (Programa de Aceleração do Crescimento) em 2008 no Rio de Janeiro ea conduziu a participação formal no comitê local do PAC.

Construção de capacidade institucional para a promoção da saúde:

pesquisa e formação

Só muito recentemente, foram criadas iniciativas mais sólidas e de caráter nacional deampliação da capacidade institucional para o trabalho com as diversas dimensões da PS.

Um exemplo significativo foi a realização, em 2006, do I Seminário sobre a Política Nacional de Promoção da Saúde ${ }^{86}$, que reuniu cerca de quatrocentos gestores das três esferas governamentais e propôs desencadear um projeto nacional de formação em larga escala de profissionais em PS, utilizando inclusive metodologias de educação à distância.

Por iniciativa da CNDSS, a SCTIE/M Sfez, em 2006, uma inédita chamada pública para pesquisa sobre determinantes e iniquidades em saúde ${ }^{87}$, visando à consolidação de uma agenda de investigações focada em PS e que aprovou 25 proje tos, com ênfase na produção de subsídios e evidências para a conformação de políticas para a produção da saúde e redução das iniquidades.

Para orientar as ações de controle das doenças não-transmissíveis e dos acidentes e violência, o M S realizou estudos nacionais de base populacional, como o Inquérito Domiciliar sobre Comportamentos de Risco e M orbidade Referida de Doenças e Agravos N ão-Transmissíveis ${ }^{88}$ (em 2003 e 2005) eo Inquérito de Fatores de Risco para Doenças Crônicas Não-Transmissíveis por Tel efone (VIGITEL) ${ }^{89}$, em 2006. Peso e condições nutricionais, exposição ao sol, tabagismo, consumo de álcool, dieta e atividade física são alguns dos fatores pesquisados, que ficam disponíveis em bases nacionais e estaduais, permitindo seu uso para o desenho de intervenções moduladas localmente. Um estudo recente ${ }^{90}$ disponibiliza dados sobre violência, que podem auxiliar no desenho de intervenções em prol da cultura da paz e de prevenção da violência.

O M S está financiando uma série de catorze estudos de avaliação da PS no país, que objetivam a análise evalidação de desenhos metodológicos e indicadores adequados à avaliação de efetividade de estratégias de promoção da saúde, a partir da troca e da produção de informações entre pesquisadores brasileiros, da aproximação crítica de experiências existentes no país e dos marcos e diretrizes definidos na PN PS ${ }^{91}$.

O Brasil constitui-senuma sub-região dentro da Oficina Regional Latino-Americana (ORLA) da IUHPE. Reúne profissionais de promoção da saúde e al gumas instituições. Realiza oficinas sobre educação em saúde de âmbitos nacional e estadual. Publicou, em 1998, o Diagnóstico das Ações de Educação em Saúdeno Brasi $\left.\right|^{192}$. Em 1996, realizou o Seminário de Formação de Recursos Humanos para a Área da Educação em Saúde ${ }^{93}$. Em 2002, a ORLA realizou no Brasil allI Conferência Regional Latino-americana dePromoção da Saúde e Educação para a Saúde, cujos resumos de trabalhos apresentados ${ }^{94}$ oferecem um panorama abrangente do que vem sendo implementado no país sob o rótulo de promoção e educação em saúde. Em 2005, realizou o I Seminário Brasileiro sobre Efetividade da Promoção da Saúde ${ }^{95}$, com expressiva participação de profissionais nacionais e estrangeiros, buscando aperfeiçoar esta dimensão fundamental da PS.

A ABRASCO, articulando instituições acadê micas no campo da saúde coletiva, inicia levantamento da produção acadêmica sobre PS e organiza diretório nacional de cursos, para reforçar a articulação e o intercâmbio de instituições entre si e com a sociedade.

Em parceria com a ENSP/Fiocruz e CIDA/ CPHA, a mesma instituição desenvolve o projeto Ações Intersetoriais para a Saúde ${ }^{96}$, com foco no intercâmbio entre grupos de distintas regiões do país, com vistas à produção coletiva de conhecimento e à ampliação da capacidade institucional para o exercício ampliado das funções da PS. Esta é a segunda etapa do programa de cooperação entre as mesmas instituições que, com financiamento da CIDA, desenvolve-se desde $1998^{97}$.

Um conjunto muito expressivo de livros, capítulos de livros, artigos em periódicos e teses de mestrado e doutorado sobre PS e áreas correlatas e afins (ver referências) foi publicado nos últimos dois a três anos no país, representando a maturidade de pesquisadores, grupos de pesquisa e instituições neste campo. Quando se comparam os dois últimos quinquênios, fica ainda mais flagrante o boom de publicações que a área teve mais recentementeno país.

Os Congressos Brasileiros de Saúde Coletiva promovidos pela ABRASCO a cada quatro anos são um espaço privilegiado para a amostragem sobre a robustez das áreas integrantes da saúde pública. Um exame sumário de seus anais, que 
vem sendo feito por equipe liderada por um dos autores deste texto para ulterior publicação, demonstra crescenteparticipação detrabal hose pôsteres, além de oficinas de trabal ho, mesas e conferências sobre PS. A abordagem da PS tem variado de campo conceitual até a descrição e análise de práticas, passando pelos campos de métodos e técnicas de PS, legislação, formação de recursos humanos etc. Quanto à origem dos profissionais autores dos trabalhos, observa-se que cerca de metade deles estão vinculados a serviços de saúde e outros tantos provêm do espaço acadêmico.

\section{Visão crítica e dificul dades a superar}

Além dos comentários críticos já feitos ao longo do texto, cabe observar que, no Brasil, as estraté gias promocionais, assim como o desenho e implementação de políticas públicas para a saúde, têm esbarrado na estrutura administrativa segmentada e burocrática do Estado, no predomínio da cultura setorial ecompetitiva, na ausência de uma política estratégica de desenvolvimento social e no predomínio da racionalidade biomé dica nas arenas da saúde.

A intersetorialidade pela saúde nas políticas públicas, na verdade, supõe uma decisão suprasetorial, expressiva de um pacto pela saúde/qualidade de vida como decisão política, a ser operacionalizada nos planos institucional, programático e orçamentário.
No plano institucional, estabelecendo um locus no aparelho estatal, acima das agências setoriais (ministérios, secretarias, etc.), explicitamente encarregado de produzir econduzir as iniciativas transversais orientadas à produção de saúde e bem-estar, através do diálogo com os diversos segmentos da sociedade e do aparelho de estado, como propõe a CNDSS 35 .

No plano programático, cuidando para que a intersetorialidade não se esterilize nas intencionalidades retóricas e em frágeis acordos, e esteja encarnada em programas concretos dirigidos a populações concretas, com objetivos, gestão e orçamentos próprios, submetidas a procedimentos de avaliação que permitam dimensionar seus impactos sobre a saúde e a qualidade de vida.

No plano orçamentário, para sublinhar que não haverá programas intersetoriais efetivos sem alocação de recursos específicos; financiar essas iniciativas somando parcelas orçamentárias de diversos órgãos induz à competição intersetorial e não à cooperação.

Contudo, como se mostrou, os progressos são evidentes nos últimos dez anos. E pelas bases políticas ede conhecimento queestão sendo construídas no presente, existem fortes indicações de que o campo da PS continuará em trajetória ascendenteno país, nos campos da política pública, da ciência e tecnologia, assim como dos movimentos sociais.

\section{Colaboradores}

PM B eAIC tiveram idêntica participação na elaboração do artigo. 


\section{Referências}

1. World Health Organization. Ottawa Charter. [site da Internet]. [acessado $2008 \mathrm{dez} 7$ ]. Disponível em:http:/ /www.wpro.who.int/NR/rdonlyres/798A711D-DC304E27-8D D 6-19561EB969CC/0/ottawa charter.pdf

2. Buss PM , organizador. Promoção da Saúde e Saúde Pública: contribuição ao debate entre as Escolas de Saúde Pública da América Latina. Rio de Janeiro: EN SP/Fiocruz; 1998. [M imeo]

3. Brasil. Ministério da Saúde. As cartas da promoção da saúde. Brasília: M inistério da Saúde; 2000.

4. Buss PM, Ferreira JR. Atenção primária e promoção da saúde. In: Ministério da Saúde. As cartas da promoção da saúde. Brasília: Ministério da Saúde; 2000.

5. Buss PM. Promoção da saúde e qualidade de vida. Cien Saude Colet [periódico na Internet]. 2000 5(1):[cerca de 15 p.]. Disponível em: http://www. scielo.br/pdf/\%0D/csc/v5n1/7087.pdf

6. Buss PM, Ferreira JRF. Local integrated and sustainable development as a strategy for 'radical health promotion' in Brazil. Promotion \& Education 2001; VII (4):25-28

7. Teixeira C. 0 futuro da prevenção. Salvador: ISC/ Casa da Saúde; 2001.

8. Buss PM. Promoção da saúde na infância e na adolescência. Rev. Bras. Saude Mater. Infant. 2001 1(3):279-282.

9. Buss PM. Promoção da Saúde da Família. Revista Brasileira de Saúde da Família 2002; 2(6):50-63.

10. Zancan L, Bodstein R, Marcondes WB, organizadores. Promoção da saúde como caminho para o de senvolvimento local. Rio de Janeiro: ABRASCO/ CIDA-CPHA/ FINEP/Fiocruz; 2002.

11. Czeresnia D, Freitas CM, organizadores. Promoção da saúde: conceitos, reflexões, tendências. Rio de Janeiro: Fiocruz; 2003

12. Buss PM. Uma introdução ao conceito de promoção da saúde. In: Czeresnia D, Freitas CM, organizadores. Promoção da saúde: conceitos, reflexões, tendências. Rio de Janeiro: Fiocruz; 2003. p. 15-38.

13. Lefevre $F$, Lefevre, AMC. Promoção de saúde: a negação da negação. Rio de Janeiro: Vieira \& Lent; 2004.

14. Buss PM, editor convidado. Perspectivas na Avaliação em Promoção da Saúde. Cien Saude Colet 2004; 9(3):515-824.

15. Carvalho SR. Saúde coletiva e promoção da saúde: Sujeito e mudança. São Paulo: Hucitec; 2005.

16. Westphal MF. Promoção da saúde e prevenção de doenças. In: Campos GWS, M inayo MCS, Akerman $M$, Drumond Júnior $M$, Carvalho $Y M$, organizadores. Tratado de Saúde Coletiva. São Paulo: Hucitec; Rio de Janeiro: ABRASC0; 2006. p. 635-667.

17. Castro $A, M$ alo $M$, organizadores.SU S: ressignificando a promoção da saúde. São Paulo: Hucitec/ OPS; 2006

18. Pereira Lima VL, Campos, NZR. Perfil descriptivosituacional del sector de promoción de la salud y educación para la salud en Brasil. In: Arroyo HV, Cerqueira MT, editores. La promoción de la salud y la educación para la salud en América Latina. San Juan: Editorial de la Universidad de Puerto Rico; 1997. p. $77-87$.
19. Westphal M F, Bógus $C M$, M endes $R$, Akerman $M$, Lemos MS. La promoción de salud en Brasil. In: Arroyo HV, organizador. La promoción de la salud en América Latina: modelos, estructuras y visión crítica. San Juan: UIPES/ORLA; 2004. p. 123-54.

20. Rocha DG. 0 movimento da promoção da saúde na década de 1990: Um estudo sobre seu desenvolvimento e difusão na saúde pública brasileira. [tese]. São PauIo (SP): Faculdade de Saúde Pública da USP; 2001.

21. Brasil. Constituição Federal. Brasília: Congresso Nacional; 1988.

22. Brasil. Leis $n^{\circ} 8.080$ e $n^{\circ} 8142$, que regulamentam 0 Sistema Ú nico de Saúde (SUS). Brasília: Congresso Nacional; 1991.

23. Andrade LOM, Barreto ICHC, Bezerra RC. Atenção primária à saúde e estratégia saúde da família. In: Campos GWS, M inayo MCS, Akerman M, Drumond Júnior $M$, Carvalho YM, organizadores. Tratado de Saúde Coletiva. São Paulo: Hucitec; Rio de Janeiro: ABRASC0; 2006. p. 783-836.

24. Ministério da Saúde. Saúde da Família. [site da Internet]. [acessado 2009 fev 7]. Disponível em: http:/ /dtr2004.saude.gov.br/dab/atencaobasica.php

25. Castro A. Institucionalização da promoção da saúde no Sistema Ú nico de Saúde. Brasília: Ministério da Saúde; $s / d$. [Mimeo]

26. Brasil. M inistério da Saúde. Política Nacional de Promoção da Saúde (documento para discussão). [site da Internet]. [acessado 2009 fev 26]. Disponível em: http://bvsms.saude.gov.br/bvs/publicacoes/politica nac prom saude.pdf

27. Brasil. M iñistério da Saúde. A construção de vidas mais saudáveis (cartilha). [site da Internet]. [acessado 2009 mar 2]. Disponível em: http://dtr2001. saude.gov.br/editora/produtos/livros/pdf/02_0178_ M.pdf

28. Brasil. Ministério da Saúde. Programa de Redução da M orbimortalidade por Acidentes de Trânsito. [site da Internet]. [acessado 2009 mar 2]. Disponível em: http://bvsms.saude.gov.br/bvs/publicacoes/ programa reducao morbi.pdf

29. Brasil. M inistério dā Saúde. Agita Brasil: Programa Nacional de Promoção da Atividade Física. [site da Internet]. [acessado 2009 mar 2]. Disponível em: http://dtr2001.saude.gov.br/editora/produtos/livros/pdf/02 0108 M.pdf

30. World Health Organization. Global Strategy on Diet, Physical Activity and $\mathrm{H}$ ealth. [site da Internet]. [acessado 2009 mar 2]. Disponível em: http://www.who. int/dietphysicalactivity/strategy/en/

31. Brasil. M inistério da Saúde. Análise da Estratégia Global para Alimentação Saudável, Atividade Física e Saúde. Brasília: Ministério da Saúde; 2004.

32. Brasil. M inistério da Saúde. Pratique Saúde. [site da Internet]. [acessado 2009 abr 6]. Disponível em: http:/ /portal.saude.gov.br/portal/saude/area.cfm?id_ area $=919$

33. Brasil. M inistério da Saúde. Política Nacional de Promoção da Saúde. [site da Internet]. [acessado 2009 abr 7]. Disponível em: http://portal.saude.gov.br/ portal/arquivos/pdf/portaria687_2006_anexol.pdf 
34. Commission on Social Determinants of H ealth. Closing the gap in a generation - Final Report of the CSDH. Geneva: WH O; 2008.

35. Comissão Nacional dos Determinantes Sociais da Saúde. As causas sociais das iniquidades em saúde no Brasil - Relatório Final da CNDSS. Rio de Janeiro: Fiocruz; 2008.

36. Brasil. M inistério da Saúde. Mais Saúde: Direito de Todos. [site da Internet]. [acessado 2009 abr 8]. Disponível em: http://bvsms.saude.gov.br/bvs/pacsaude/

37. Brasil. Ministério da Saúde. Programa de Saúde da Família. [site da Internet]. [acessado 2009 jan 3]. Disponível em: http://dtr2004.saude.gov.br/dab/ abnumeros.php\#numeros

38. Brasil. M inistério da Saúde. III M ostra Nacional de Produção em Saúde da Família. [site da Internet]. [acessado 2009 jan 3]. Disponível em: http://dtr2004. saude.gov.br/dab/evento/mostra/mostra_login.php

39. Brasil. M inistério da Saúde. Política Nacional de Alimentação e Nutrição. 2a ed. rev. [Série B. Textos Básicos de Saúde]. Brasília: Ministério da Saúde/ Secretaria de Atenção à Saúde/D epartamento de Atenção Básica; 2003.

40. Brasil. Lei no 11.265/06. Norma Brasileira de Comercialização de Alimentos para Lactentes e Crianças de Primeira Infância, Bicos, Chupetas e Mamadeiras (NBCAL). [site da Internet]. [acessado 2009 jan 3]. Disponível em: http://e-legis.anvisa. gov.br/leisref/public/showAct.php?id=21635\& word

41. ANVISA. Resolução sobre rotulagem de alimentos industrializados. [site da Internet]. [acessado 2009 jan 3]. Disponível em: http://www.anvisa.gov.br/ alimentos/legis/especifica/rotuali.htm

42. Brasil. Ministério da Saúde. Suplementação de vitamina A. [site da Internet]. [acessado 2009 jan 3]. Disponível em: http://www.in.gov.br/materias/xml/ do/secao 1/1524757.xml

43. Brasil. M inistério da Saúde. Suplementação de ferro e ácido fólico em alimentos. [site da Internet]. [acessado 2009 jan 3]. Disponível em: http://www.in.gov. $\mathrm{br} / \mathrm{materias} / \mathrm{xml} / \mathrm{do} / \mathrm{secao} 1 / 1524757 . x \mathrm{ml}$

44. Brasil. M inistério da Saúde. Guia Alimentar para a População Brasileira. Brasília: Ministério da Saúde; 2006.

45. ANVISA abre consulta pública sobre regras para propaganda de alimentos. [site da Internet]. [acessado 2009 jan5]. Disponível em: http://portal.saude. gov.br/portal/aplicacoes/noticias/noticias_detalhe. cfm?co_seq_noticia $=28301$

46. Brasil. M inistério da Saúde. Programas e projetos de promoção da saúde. [site da Internet]. [acessado 2009 jan 3]. Disponível em: http://www.saude.gov.br

47. Brasil. M inistério da Saúde. Instituto Nacional do Câncer. Programa Nacional de Controle do Tabagismo e Outros Fatores de Risco de Câncer. [site da Internet]. [acessado 2009 jan 3]. Disponível em: http://www.inca.gov.br/tabagismo/frameset.asp? item =programa\&link=programa_de_tabagismo.pdf

48. Brasil. Decreto $n^{\circ} 5.658$, de $2 / 01 / 2006$, que promulga a Convenção-Quadro sobre controle do uso do tabaco. [site da Internet]. [acessado $2009 \mathrm{fev}$ 8]. Disponível em: http://www2.mre.gov.br/dai/m_5658_ 2006.htm
49. Brasil. Ministério da Saúde. Política de Atenção Integral a U suários de Álcool e Outras Drogas. [site da Internet]. [acessado 2009 jan 3]. Disponível em: http://dtr2001.saude.gov.br/editora/produtos/livros/pdf/03_0277_\%20M.pdf

50. Brasil. M inistério da Saúde. Política Brasileira de AIDS: Principais resultados e avanços 1994-2002. [site da Internet]. [acessado 2009 jan 3]. Disponível em: http:/ /bvsms.saude.gov.br/bvs/publicacoes/politica_94_ 02.pdf

51. Brasil. M inistério da Saúde. Plano Estratégico: Programa Nacional de DST e AIDS 2005. [site da Internet]. [acessado 2009 jan 3]. Disponível em: http:// bvsms.saude.gov.br/bvs/publicacoes/plano estrategico.pdf

52. Brasil. M inistério da Saúde. Programa de Educação e Prevenção de DST e AIDS. [site da Internet]. [acessado 2009 jan 3]. Disponível em: http://www.aids. gov.br/final/prevencao/estrategias.htm

53. Brasil. M inistério da Saúde. Campanhas de educação e comunicação em saúde. [site da Internet]. [acessado 2009 jan 3]. Disponível em: http://portal.saude. gov.br/portal/saude/area.cfm?id_area $=137$

54. Carvalho Al. Conselhos de Saúde no Brasil: Participação cidadã e controle social. Rio de Janeiro: FASE/ IBAM; 1995.

55. Brasil. M inistério da Saúde. Incentivo à participação popular e controle social no SUS: Textos técnicos para conselheiros de saúde. Brasília: M inistério da Saúde; 1998.

56. Brasil. M inistério da Saúde. Conselho Nacional de Saúde. Seminário N acional Saúde e Ambiente com controle social. Brasília: Ministério da Saúde; 2003.

57. Faleiros VP, Vasconcelos LCF, Silva JFS e Silveira RM G. A construção do SUS: H istórias da reforma sanitária e do processo participativo. Brasília: Ministério da Saúde; 2006.

58. Brasil. M inistério da Saúde/SVS. Comitê Temático Interdisciplinar de Saúde e Ambiente (CTI-SA). [site da Internet]. [acessado 2009 jan 5]. Disponível em: http://portal.saude.gov.br/portal/saude/visualizar_ texto.cfm?idtxt=21594

59. Vasconcelos EM. Educação popular e a atenção à saúde da família. São Paulo: Hucitec; 2006.

60. Valla VV, Stotz EM, organizadores. Educação, saúde e cidadania. Petrópolis: Vozes; 1996.

61. Brasil. Ministério do Desenvolvimento Social e Combate à Fome. Bolsa Família. [site da Internet]. [acessado 2008 dez 27]. Disponível em: http:// www.mds.gov.br/bolsafamilia

62. Ashton J, Grey P, Barnard K. Healthy cities: WHO's new public health initiative. Health Promotion 1986; 1(3):319-323.

63. Ashton J, Seymour H. The new public health. London: Open University Press; 1988.

64. Organização Pan-americana da Saúde. M unicípios e comunidades saudáveis: Guia dos prefeitos para promover qualidade de vida. Brasília: OPS; 2005.

65. Mendes EV. U ma agenda para a saúde. São Paulo: Hucitec; 1996.

66. M endes EV, organizador. A organização da saúde no nível local. São Paulo: Hucitec; 1998.

67. Mendes EV. Os grandes dilemas do SUS. Salvador: Casa da Qualidade Editora; 2001. 
68. Ferraz ST. Cidades saudáveis: uma urbanidade para 2000. Brasília: Paralelo 15; 1999.

69. Sperandio AM G, organizador. 0 processo de construção da Rede de M unicípios Potencialmente Saudáveis. Campinas: IPES Editorial; 2004.

70. Sperandio AM G, Correa CRS, Serrano M M, Rangel HA. Caminho para a construção coletiva de ambientes saudáveis - São Paulo, Brasil. Cien Saude Colet 2004; 9(3):643-654.

71. Centro de Estudos, Pesquisa e Documentação em Cidades Saudáveis. [site da Internet]. [acessado 2008 dez 27]. Disponível em: http://www.cidades saudáveis.org.br

72. Westphal MF. O movimento cidades / comunidades saudáveis: um compromisso com a qualidade de vida. Cien Saude Colet 2000; 5(1):39-51.

73. Projeto M unicípios Saudáveis no Nordeste Brasileiro. [site da Internet]. [acessado $2008 \mathrm{dez} 7$ ]. Disponível em: http://www.nusp.ufpe.br/projeto4.htm

74. M oysés SJ, Moysés ST, Krempel MC. Avaliando o processo de construção de políticas públicas de promoção da saúde: A experiência de Curitiba. Cien Saude Colet 2004; 9(3):627-641.

75. Andrade LOM. A saúde e o dilema da intersetorialidade. São Paulo: Hucitec; 2006.

76. Becker $D$, Edmundo KB, Guimarães W, VasconceIos MS, Bonatto D, Nunes NR, Baptista AP. N etwork of healthy communities of Rio de Janeiro, Brazil. Promotion \& Education 14(2):101-102.

77. Becker D, Edmundo K, Nunes NR, Bonatto, D, Souza R. Empowerment e avaliação participativa em um programa de desenvolvimento local e promoção da saúde. Cien Saude Colet 2004; 9(3):655-667.

78. Escolas Promotoras da Saúde da Secretaria Municipal de Saúde da Cidade do Rio de Janeiro. [site da Internet]. [acessado $2008 \mathrm{dez}$ 7]. Disponível em: http://www.saude.rio.rj.gov.br/saudeescolar

79. Escolas Promotoras da Saúde de Santos. [site da Internet]. [acessado 2008 dez 7]. Disponível em: http://www.santos.sp.gov.br/comunicacao/escola/ escola.html

80. Sociedade Brasileira de Pediatria.[site da Internet]. [acessado 2008 dez 7]. Disponível em: http:// www.sbp.com.br/img/cadernosbpfinal.pdf

81. Grupo de Trabalho sobre Promoção da Saúde e Desenvolvimento Local, Integrado e Sustentável. [site da Internet]. [acessado $2008 \mathrm{dez}$ 7]. Disponível em: http://www.abrasco.org.br/grupos/arquivos/20060719172955.pdf

82. Grupo de Trabalho sobre Promoção da Saúde e Desenvolvimento Local, Integrado e Sustentável. [site da Internet]. [acessado $2008 \mathrm{dez} 7$ ]. Disponível em: http://www.abrasco.org.br/grupos/arquivos/20060719173717.pdf

83. Grupo de Trabalho sobre Promoção da Saúde e Desenvolvimento Local, Integrado e Sustentável. [site da Internet]. [acessado 2008 dez 7]. Disponível em: http://www.abrasco.org.br/grupos/arquivos/20060719173238.pdf

84. Akerman M. Saúdee desenvolvimento local. São Paulo: Hucitec; Brasília: OPAS; 2005.

85. Bodstein R, Zancan L, Ramos CL, M arcondes WB. Avaliação da implantação de desenvolvimento integrado em $M$ anguinhos: impasses na formulação de uma agenda local. Cien Saude Colet 2004; 9(3):593-604.
86. Brasil. M inistério da Saúde. Seminário sobre Política Nacional de Promoção da Saúde. [site da Internet]. [acessado 2009 jan 2]. Disponível em: http://portal web05.saude.gov.br/portal/arquivos/pdf/folder seminario.pdf

87. Brasil. M inistério da Saúde. Edital de pesquisa sobre determinantes sociais da saúde. [site da Internet]. [acessado 2008 dez 7]. Disponível em: http://portal. saude.gov.br/portal/arquivos/pdf/Edital\%20 Determinantes\%20Sociais.pdf

88. Brasil. M inistério da Saúde. Instituto Nacional do Câncer. Inquérito domiciliar sobre comportamentos de risco emorbidade referida de doenças e agravos não transmissíveis. [site da Internet]. [acessado 2008 dez 7]. Disponível em: http://www.inca.gov.br/inquerito

89. Brasil. M inistério da Saúde. VIGITEL [site da Internet]. [acessado 2009 out 1]. Disponível em: http:/ /portal.saude.gov.br/portal/aplicacoes/noticias/ noticias detalhe.cfm?co seq noticia $=27861$

90. M inayo MCS, Deslandes SF, organizadoras. Análise diagnóstica da Política Nacional de Saúde para Redução de Acidentes e Violências. Rio de Janeiro: Fiocruz; 2007.

91. Brasil. Ministério da Saúde. Secretaria de Vigilância à Saúde. Avaliação da promoção da saúde. [site da Internet]. [acessado 2009 jan 4]. Disponível em: http://portal.saude.gov.br/portal/saude/visualizar texto.cfm?idtxt $=24559$

92. International Union of $\mathrm{H}$ ealth Promotion and Health Education/Oficina Regional Latino-Americana. Diagnóstico das Ações de Educação em Saúde no Brasil. [site da Internet]. [acessado 2008 dez 27]. Disponível em: http://openlink.br.inter.net/ vllima.orla/diagno.htm

93. International Union of $\mathrm{H}$ ealth Promotion and Health Education/Oficina Regional Latino-Americana. Seminário de Formação de Recursos H umanos para a Área da Educação em Saúde. [site da Internet]. [acessado 2008 dez 7]. Disponível em: http:// openlink.br.inter.net/vllima.orla/semonovo.htm

94. III Conferência Regional Latino-americana de Promoção da Saúde e Educação para a Saúde. [site da Internet]. [acessado 2009 out 1]. Disponível em: http://hygeia.fsp.usp.br/cepedoc/fr-resumo.htm

95. Westphal MF, Wallerstein $\mathrm{N}$, editors. Evaluation of health promotion effectiveness in Brazil. Proceedings from the 1st Brazilian Seminar on Health Promotion Effectiveness M ay 10th to 13th, 2005, Rio de Janeiro, Brazil. Promotion \& Education 2007; Supl. 1.

96. Escola Nacional de Saúde Pública. Projeto de Cooperação em Promoção da Saúde ABRASCO-CPHAENSP/FIOCRUZ. Rio de Janeiro: ABRASCO-CPHAENSP/Fiocruz; 2006. [M imeo]

97. Zancan L, Adesse L. Informe sobre a Cooperação Brasil-Canadá em Promoção da Saúde. Cien Saude Colet 2004; 9(3):739-744.

Artigo apresentado em 02/07/2009

Aprovado em 18/08/2009

Versão final apresentada em 30/09/2009 